\title{
Bipartite Ossification
}

National Cancer Institute

\section{Source}

National Cancer Institute. Bipartite Ossification. NCI Thesaurus. Code C124500.

A finding of two unfused primary ossification centers, as indicated by staining, usually resulting in two separate and distinct bones. 